\title{
Pupil dilations following pairs of identical and related to-be-remembered words
}

\author{
ANTHONY MAGLIERO \\ University of Texas, Arlington, Texas
}

\begin{abstract}
Two experiments are reported in which the spacing between pairs of identical (Experiment 1) or pairs of related (Experiment 2) to-be-remembered words were varied while pupil diameter and frequency judgments were measured. In Experiment 1, frequency judgments increased with increases in spacing length. In Experiment 2, frequency judgments decreased with increases in spacing length. In both experiments, however, pupil dilations increased with increases in spacing length. These results are interpreted as supporting theories that argue that massed repetitions require less processing than spaced repetitions. It is argued that this deficiency in processing reduces retention of massed repetitions of identical words. For massed presentation of related words, organizational strategies can be used with little effort to increase retention.
\end{abstract}

A common finding in memory research is that spaced repetitions of to-be-remembered words result in better retention than do massed repetitions. Many theories have been proposed to account for the spacing effect, but none has received a consensus of support. Several accounts of the spacing effect propose that massed repetitions receive less processing than do spaced repetitions. Underwood (1969) suggested that massed repetitions are not attended to as well as spaced repetitions. Shaughnessy, Zimmerman, and Underwood (1972) tested this voluntary-attention explanation of the spacing effect by allowing subjects to control the time spent studying each to-be-remembered item. They found that repeated items were given less study time when the repetitions were massed than when they were spaced. Damaging evidence against the voluntary-attention hypothesis, however, was produced by Hintzman, Summers, Eki, and Moore (1975). In Experiment I, they paired some of the repeated items with an incentive tone signaling high payoff for later retention. The incentive tone elevated frequency judgments at all spacings, but the spacing effect was the same in the notone and the tone conditions. In Experiment II, subjects studied some lists aloud by reciting each word three times. Again, this failed to attenuate the spacing effect

This paper is based on a dissertation submitted to the University of Texas at Arlington in partial fulfillment of the requirements for the PhD degree. I would like to express my gratitude to James R. Erickson, Ira H. Bernstein, Robert J. Gatchel, James N. Bowen, and Raymond L. Jackson for support and guidance. Additional thanks are extended to Edward Shoben for reviewing an earlier version of the manuscript, to Ellen Gorthey, Beth Huggins, Cheryl Buckner, and Elizabeth Gaas for assistance in data collection and scoring, and to Betty Bilotta for typing. Requests for reprints should be sent to the author at Applied Science Associates, Inc., P.O. Box 158, Valencia, Pennsylvania 16059 . (compared with a silent study condition). The final experiment measured eye fixations to pictures and found no effect of spacing length. The three experiments, then, produced no support for a voluntary-attention explanation of the spacing effect.

As an alternative to the voluntary-attention theory, Hintzman (1974; Hintzman, Summers, \& Block, 1975b) has proposed a habituation-recovery hypothesis. According to this hypothesis, presentation of an item produces habituation of the internal representation of that item, leading to a raising of the threshold for activation. Recovery from habituation begins when the item is no longer being studied. If a repetition occurs before recovery from habituation is complete, the internal representation will be only partially activated. Thus, only with long spacings will the second presentation fully activate the internal representation. If accurate frequency judgments of a repeated word depend upon the strength of the multiple activations, then this theory can explain the spacing effect.

The hypothesis has no direct support evidence yet. Hintzman et al. (1975b) theorized that increasing the stimulus duration and the number of presentations would cause "overhabituation," but these manipulations did not change the spacing effect. An interesting post hoc finding did appear, however, in that a brief interruption (.8-sec blank time) of the visual stimuli significantly increased recognition (compared with uninterrupted stimuli). Such a result is consistent with the habituation-recovery hypothesis if some recovery occurred during the slight interruption.

A problem with the habituation-recovery hypothesis is that it appears to be inconsistent with other data. Many studies have shown that massed presentations of identical or similar items lead to faster reaction times (RTs) on the second item in a variety of tasks (Berteison, 1963; Fischler \& Goodman, 1978; Keele, 1969; Neely, 
1977; Posner \& Snyder, 1975). The habituation hypothesis is based on an inhibitory adaptation mechanism that would seem to predict that massed repetitions lead to slower decisions. It could be argued that the habituation hypothesis is only concerned with processes related to deliberate encoding into memory and, hence, that these RT studies are irrelevant. However, with this restriction, the theory is now unable to account for the spacing effect found in incidental learning (McFarland, Rhodes, \& Frey, 1979; Rose, 1980; Rose \& Rowe, 1976).

A different approach, presented by Jacoby (1978), emphasizes an analogy between memorizing a word and solving a problem. When a to-be-remembered word is initially presentd to subjects, they are faced with a problem. What operations can be performed to enhance the memorability of a word? In response, subjects may create an image, elaborate with synonyms, form interitem associations, and so forth. If the item is repeated immediately, the entire process is not repeated, because the product of the previous elaboration can be retrieved easily. As the length of spacing between repetitions is increased, the result of the earlier elaborations can no longer be retrieved easily and more elaborations must be constructed rather than remembered. These constructed events are better retained than remembered events because they are more distinctive (Jacoby \& Craik, 1978; Lockhart, Craik, \& Jacoby, 1976) or because they are processed to a deeper level (Craik \& Lockhart, 1972).

To support his position, Jacoby (1978) engaged subjects in a word-completion task similar to that required in a crossword puzzle. Subjects were presented with repetitions of pairs of related words (e.g., foot shoe). For some repetitions, letters were missing from the second word (the construction condition). For other repetitions, the whole word was presented (the read condition). For these read repetitions, retention was low for both massed and distributed presentations. For the construction condition, retention of the distributed repetitions was superior to retention of the massed repetitions. As predicted by the theory, conditions in which the repeated word was easily remembered produced low retention.

A position somewhat similar to Jacoby's (1978) has been proposed by Rose (1980; Rose \& Rowe, 1976). This levels-of-processing approach states that, if an item is repeated, an attempt is made to retrieve the previous encoding of the item. If the spacing is short, this retrieval is accomplished with little effort and with shallow processing. If the spacing is long, more effort and deeper processing are required as the subjects attempt to reconstruct the original encoding. If it is assumed that a deeper level of processing leads to better long-term availability (Craik \& Lockhart, 1972), then this theory can account for the spacing effect. A test of the levels-of-processing theory of the spacing effect was performed by Rose (1980). The theory predicts that encoding context will affect the depth-ofprocessing given to a repetition and, hence, memory of the repetition. If an item is presented with the same encoding context at each presentation, then repetitions with short spacings should receive shallow processing after a scan of short-term memory. Similar repetitions with long spacings should receive deep processing, because the previous encoding cannot be recovered easily. If a different encoding context is presented with each presentation, then all repetitions (regardless of spacing) should receive deep processing. The levels-of-processing theory, therefore, predicts that a constant-encodingcontext condition should show a larger effect of spacing than a different-context condition. This prediction was supported by the results of Rose (1980).

There is a common theme in the theories of Jacoby (1978) and Rose (1980; Rose \& Rowe, 1976). Both emphasize the importance of operations performed on the to-be-remembered items and the consequences of bypassing these operations by easily retrieving the results of earlier presentations. These theories (along with the habituation-recovery hypothesis) may be termed deficient-processing theories, because they predict that massed repetitions will receive less processing than will spaced repetitions. Direct supporting evidence for deficiency theories is lacking, possibly because of the difficulty of measuring the amount of processing allocated to items. Johnston and Uhl (1976) used a probeRT task (Posner \& Boies, 1971) to measure processing effort during the presentation of repeated to-beremembered words. Consistent with the predictions of a deficient-processing theory, they found that responses to probe tones accompanying massed repetitions were quicker than responses to probe tones accompanying spaced repetitions. A problem with this methodology, however, is that the requirement to perform dual tasks may affect unpredictably performance on the primary memory task (Hintzman \& Stern, 1977).

Ideally, the amount of processing should be measured unobtrusively. Psychophysiological responses appear to meet this criterion. For example, Kahneman and associates (1973; Kahneman \& Beatty, 1966; Kahneman, Beatty, \& Pollack, 1967; Kahneman \& Peavler, 1969) have demonstrated a relationship between processing effort and pupil dilation by showing that increas. ing the memory load increases pupil diameter. These data suggest that deficient-processing theories of the spacing effect can be tested by measuring psychophysiological responses elicited by the to-be-remembered items. The spacing between repeated items should affect the responses elicited by repetitions, with massed repetitions recieving smaller responses than spaced repetitions. Such a test was performed by Silverstein (1977), who examined the heart rate and skin conductance responses following to-be-remembered items and found similar patterns in the psychophysiological-response and verbal-recall data. Physiological responses to repeated items were smaller for massed than for spaced repetitions. Recall data showed the typical spacing effect; that is, spaced repetitions were better recalled than were massed repetitions.

Unfortunately, there is a possible alternative explana- 
tion for the Silverstein (1977) results. Heart rate and skin conductance responses are commonly used to study habituation (see Graham, 1973), because they reduce in magnitude very quickly. It has been established that short interstimulus intervals (ISIs) lead to faster shortterm habituation than do long ISIs (Davis, 1970; Gatchel $\&$ Gaas, 1976). This suggests that the length of spacing between identical words could have affected a habituation process that may have little relationship with the amount of mental processing. In contrast, the evidence linking pupil dilation to mental effort is much stronger (see Kahneman, 1973).

\section{EXPERIMENTS 1 AND 2}

In Experiment 1, pupil dilation and heart rate changes elicited by repeated items were measured while the spacing between repetitions was manipulated. Experiment 1 used a procedure designed to produce the Hintzman (1974, pp. 79-81) spacing effect. The retention measure was frequency judgments. The spacing interval was zero, one, four, or eight intervening items, and the list ISI was $6 \mathrm{sec}$. Thus, the time between repetitions was $6,12,30$, or $54 \mathrm{sec}$. A 6-sec ISI was chosen to allow pupil dilations to recover between items (Kahneman \& Peavler, 1969, had found recovery with a 4-sec ISI).

Experiment 2 varied the length of spacing between pairs of related words. Glanzer (1969) and Hintzman, Summers, and Block (1975a) varied the length of spacing between pairs of related words and found that retention was superior at the short spacings. Therefore, it was expected that the effects of spacing on retention would differ in Experiments 1 and 2. Of interest was a comparison of the effects of spacing on psychophysiological responses in Experiments 1 and 2. Since the two experiments employed the same basic design and were run concurrently, they are reported together here.

\footnotetext{
Method

Materials and Apparatus. Ninety-six categories were selected from the Battig and Montague (1969) and Shapiro and Palermo (1970) category norms. For Experiment 1, one of the six most common responses was chosen from each of the categories to form a stimulus pool of 96 words, none of which were homophones or homographs. Three lists were constructed from this pool by randomly assigning 24 words each to a frequency of 0 or 1 and 48 words to a frequency of 2 . Items assigned a frequency of 0 appeared only on the frequency-judgment test sheet. Of the 48 words occurring twice, 12 each were presented at spacings of $0,1,4$, or 8 intervening items. Each list was 140 items long and included 20 filler items (common nouns that were not from the selected categories), 12 at the beginning and 8 at the end of the list. The 120 experimental items (including repetitions) were arranged in blocks of 40 each. Within each block, there were 8 single-presentation items and 4 doublepresentation items at each of the four spacings. On the frequency. judgment test sheet, the 96 words in the pool were presented in random order, and the subjects were asked to estimate the frequency with which each word had been presented. They were told to guess when they were uncertain and to give a judgment
}

of 0 if the word had not occurred. They were instructed that 0,1 , and 2 were the only possibilities.

Experiment 2 used the same 96 categories as Experiment 1. Three lists were constructed by, again, randomly assigning 24 categories each to a frequency of 0 or 1 and 48 categories to a frequency of 2. The presentation lists did not contain the category names but contained zero, one, or two of the six most common responses listed in the category norms. Specific instances of each category were chosen in order to minimize intercategory relatedness of the items. The construction of the lists was the same as in Experiment 1. On the frequency test sheet, all 96 category names were presented. The subjects were told to judge how many words that they had heard were from each of the category titles listed. They were told to guess if they were uncertain and to give a judgment of 0 if no words from a category had occurred. If they were uncertain as to which category a remembered item belonged, they were told to assign it to the category that seemed most appropriate. ${ }^{3}$

The lists were recorded by a female speaking in a monotone at approximately $60 \mathrm{~dB}$ (as measured on scale Cs of a General Radio Company sound-level meter) on a Sony TC-650 tape deck. The words were read at a rate of one word every $6 \mathrm{sec}$ and were presented to subjects over a pair of Koss Pro-4AA headphones. Pupil size was recorded with a Sony AVC-3600 video camera supplemented with a set of three Hoya close-up lenses having a combined power of +7 . Pupil-size videotapes were stored on a Sony AV-3600 video recorder and were measured on a Magnavox 58.4-cm (diagonal measure) black-and-white television monitor. The magnification of the resulting pupil image was approximately 28 times that of the original pupil size.

A Grason-Stadler E7300A-1 voice-operated relay was used to record clicks on the videotape, indicating the occurrence of each word. This allowed pupil diameter to be scored by an observer who was blind with respect to which type of word occurred. Pupil diameter was measured 0,1 , and $2 \mathrm{sec}$ after item onset by stopping the video recorder and measuring the pupil image on the monitor with a ruler.

A General Radio Company random-noise generator was used to generate $55 \mathrm{~dB}$ of white noise presented over a $15.25-\mathrm{cm}$ speaker placed on the floor adjacent to the subject. Heart rate was continuously monitored throughout the experiment on a Narco Biosystems physiograph. Stainless steel plate electrodes $(8 \times 5 \mathrm{~cm})$ were attached to the inside of each forearm, and a Beckman silver/silver-chloride electrode (1-cm diam) was attached to the elbow for use as a ground reference.

In order to provide sufficient lighting for the video recording, the chamber was illuminated by overhead fluorescent lighting and two 150-W light bulbs to the side of and facing away from the subject. The resulting background illumination was approximately $80 \mathrm{fL}$ as measured by a Photo Research Spectra brightness spot meter.

Procedure. The subjects were tested individually in a soundattenuating chamber. They were told that the purpose of the experiment was to measure physiological changes during a memory task. They were instructed to listen to and study the words for a memory test, the nature of which was not specified. After the instructions, the heart rate electrodes were attached. The subjects sat in a comfortable chair with the head positioned on a chinrest. The front edge of the camera lens was positioned approximately $13.3 \mathrm{~cm}$ from the subject's reported dominant eye. A white cardboard shield $(22 \times 22 \mathrm{~cm})$ was placed around the lens. The experimenter remained behind the camera to make any necessary adjustments of the camera focus during list presentation. The cardboard shield served the dual purpose of preventing the subject from being distracted by the experimenter's movements and increasing the amount of indirect light on the subject's eye.

Subjects. In Experiment 1, the subjects were 24 undergraduates who were enrolled in introductory psychology courses and who volunteered for the experiment in partial fulfill- 
fulfillment of a course requirement. Pupil dilation data from 10 subjects could not be scored because of dark irises, excessive blinking, or excessive head or eye movements, leaving 14 subjects for whom heart rate, pupil dilation, and memory data were available. In Experiment 2, the subjects were 51 undergraduates from the same subject pool as in Experiment 1. The pupil dilation data from 26 subjects could not be scored, leaving 25 subjects for whom heart rate, pupil dilation, and memory data were available. All data reported here are based only on subjects for whom complete data were available. ${ }^{2}$

\section{Results $^{3}$}

Frequency judgments. Mean frequency judgments for Experiments 1 and 2 are presented in Figure 1. A oneway repeated-measures analysis of variance (ANOVA) was used to analyze only data from the items that occurred twice.

For Experiment 1, the linear trend was significant $[F(1,39)=12.2$, MSe $=0.043]$, but the quadratic com. ponent was not $(F<1)$. In Experiment 2, both the linear $[F(1,72)=5.6$, MSe $=0.049]$ and the quadratic $[F(1,72)=5.5]$ trends were significant. To examine the significance of the slight nonmonotonic trend in the data, frequency judgments at spacings of four and eight were compared and found not to significantly differ $[\mathrm{t}(24)=1.15]$.

Heart rate. Interbeat intervals (IBIs) were scored by measuring the distance between the paper recordings of the electrical event associated with the ventricular contraction of each heart beat (QRS spike). This distance was then converted to milliseconds. The first three IBIs poststimulus and two stimulus-concurrent IBIs were scored. These data were analyzed by a 5

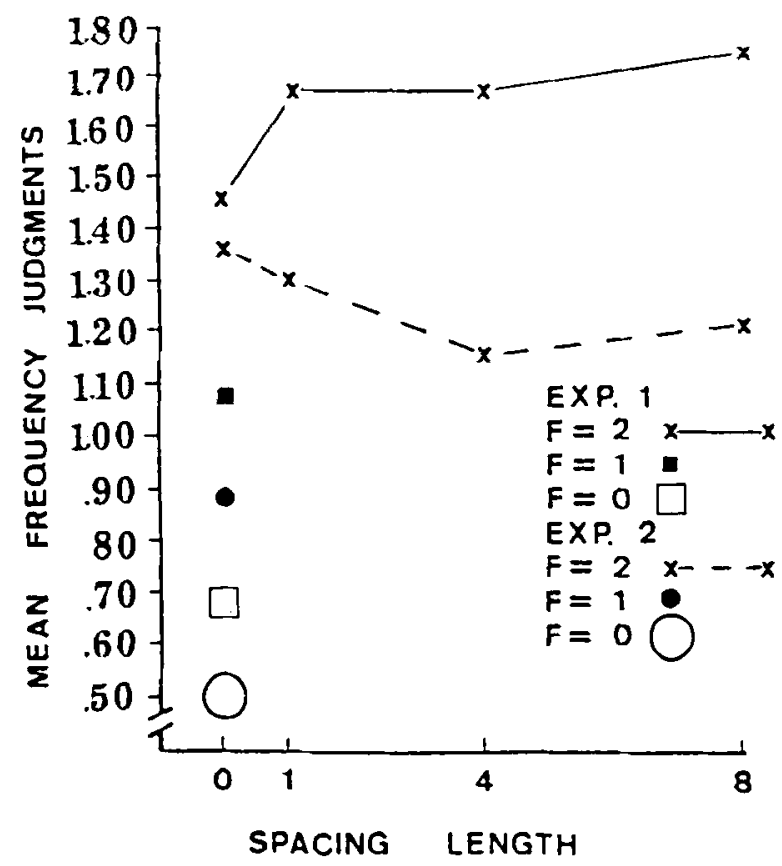

Figure 1. Mean frequency judgments for Experiments 1 and 2 as a function of word frequency $(F)$ and spacing length. (item type) $x 5$ (beats) repeated-measures ANOVA. For both Experiments 1 and 2, the main effects and their interaction produced an $F<1$. The lack of a beat effect indicates that no consistent heart rate change was elicited by item presentation. This was probably because of the short ISI used here. Graham (1970) commented that long ISIs (10 sec or more) are needed to allow one response to recover to baseline before the next begins. Shortening the ISI may disrupt any discernible heart rate responses."

Pupil dilations. The measured pupil diameter for 1 and $2 \mathrm{sec}$ poststimulus were converted to percent change from the 0 -sec diameter. These data were analyzed by a 2 (seconds) x 5 (item type) repeated-measures ANOVA. Figure 2 presents these data for both Experiments 1 and 2. Since the seconds factor is not theoretically critical, the data in Figure 2 are averaged over 1 and $2 \mathrm{sec}$ for illustrative purposes. From inspection of Figure 2, it can be seen that, in Experiment 1, repeated items at short spacings ( 0 or 1$)$ were followed by pupillary constrictions or small dilations, whereas repeated items at longer spacings were followed by larger dilations. Reflecting these trends, the effects of item type $[\mathrm{F}(4,52)=21.2, \mathrm{MSe}=4.8]$ and seconds $[\mathrm{F}(1,13)$ $=16.4, \mathrm{MSe}=1.5]$ were significant, but the interaction was not $(F<1, \mathrm{MSe}=8.2)$. The significant effects for seconds reflect a decrease in pupil diameter from 1 to $2 \mathrm{sec}$ after item presentation.

Combining over seconds, a trend analysis was used to examine the relationship between pupil changes to repeated items and the length of spacing between repetitions. Both the linear $[F(1,52)=24.4]$ and the quadratic $[F(1,52)=11.1]$ trends were significant.

To examine the relationship between pupillary responses and frequency judgments for repeated items in Experiment 1, a Pearson product moment correlation between mean frequency judgments and percent change in pupil diameter was calculated for each subject. These correlations varied widely, ranging from -.52 to 96 . For six subjects, the correlation was greater than .55 . Because of the small number of data points and the large intersubject variability, no significance tests have been applied to these data.

For Experiment 2, the pupillary results were obviously very similar to those of Experiment 1 (Figure 2). Presentation of related items at short spacings elicited pupillary constrictions, whereas similar presentations at longer spacings produced dilations. Again, the effect of item type $[\mathrm{F}(4,96)=25.4, \mathrm{MSe}=2.5]$ and seconds $[F(1,13)=25.8, \mathrm{MSe}=2.2]$ were significant, but their interaction was not $[\mathrm{F}(4,96)=1.55, \mathrm{MSe}=1.08]$. As in Experiment 1, the significant effect for seconds reflects only a decrease in pupil diameter from 1 to $2 \mathrm{sec}$ after item presentation. Combining over seconds, the trend analysis shows that both the linear $[F(1,96)=$ 42.0] and quadratic $[F(1,96)=7.4]$ components were significant. 


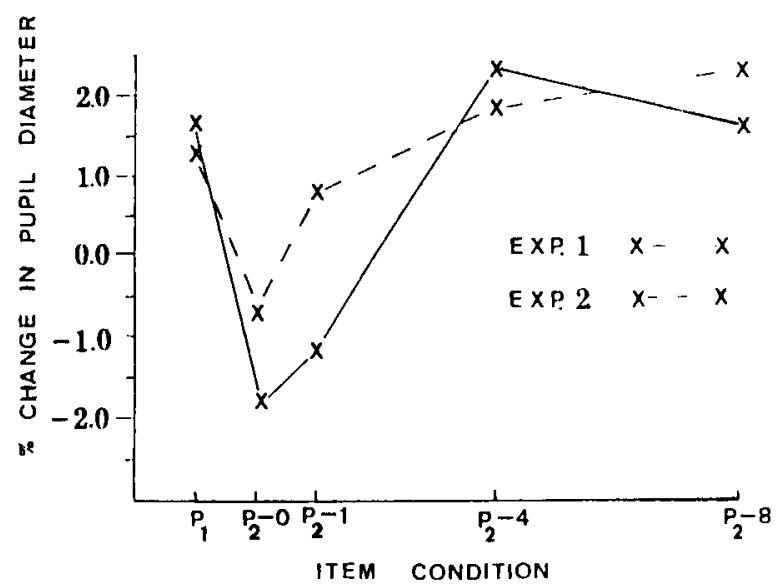

Figure 2. Mean pupillary responses for Experiments 1 and 2. The initial presentation is indicated by $P_{1}, P_{2}-n$ indicates repeated items, where $n$ is the number of intervening words.

\section{DISCUSSION}

The frequency-judgment data of Experiments 1 and 2 are in agreement with those of several earlier studies. Many studies (e.g., Hintzman et al., 1975b) have produced the spacing effect observed in Experiment 1. Two studies (Glanzer, 1969; Hintzman et al., 1975a) have also produced the related-word spacing effect found in Experiment 2. Although the frequency-judgment data from the two experiments show different patterns, the pupil dilation results are similar. A theory of spacing effect(s) should provide an explanation for both the pupillary and the frequency-judgment data. This discussion will initially center on the pupillary data before examining the retention results.

In both Experiments 1 and 2, small dilations or constrictions were observed at the short spacings, and relatively large dilations were observed at the longer spacings. According to Kahneman (1973, pp. 14-15), the magnitude of pupillary change is determined largely by task difficulty, not by voluntary control. Voluntary control over pupillary response is essentially limited to the decision to perform the task involved. If the decision is made to complete the task, task difficulty limits the amount of mental effort. A large effort (and, hence, a large pupil dilation) cannot voluntarily be allocated to an easy task.

With these conclusions in mind, two possible interpretations of the pupillary data are suggested. One is simply that subjects voluntarily decide not to proceed with the task (do not study the item) at the short spacings. This explanation does not seem feasible for two reasons. First, a voluntary-attention theory of the same-word-spacing effect has been convincingly ruled out by Hintzman et al. (1975). Second, in Experiment 2, the short spacings led to superior retention. Obviously, these words were not ignored, and yet pupillary constrictions and small dilations were observed.
An alternative explanation is that the nature of the memory task is limiting the amount of effort that can be allocated at the short spacings. The deficient-processing theories of Hintzman (1974; Hintzman et al., 1975b), Jacoby (1978), and Rose (1980; Rose \& Rowe, 1976) all provide for a mechanism that would restrict effort to massed presentations of identical or related words. For Hintzman's habituation-recovery hypothesis, two assumptions must be adopted for the position to account for the pupillary data of the two experiments. First, it must be assumed that related words share aspects of their representations in memory. The initial presentation of an item adapts the representation of the observed and related items. Massed repetitions of identical or related items will now lead to only partial activation of the representations. A second assumption, that attenuated activation will restrict pupil dilations to those items, must now be invoked. Although these assumptions are reasonable, the theory suffers from lack of direct empirical support.

The theories of Jacoby (1978) and Rose (1980; Rose \& Rowe, 1976) are both supported by the pupillary data of Experiments 1 and 2. Both of these positions emphasize the importance of the elaborations following an item presentation. If the product of earlier elaborations is easily retrieved, little effort is required by a repetition. To account for the pupillary data of Experiment 2, it need only be assumed that similar operations follow similar items. For example, if the items "dog" and "cat" are presented on consecutive trials, the elaborations elicited by the first word can be easily retrieved and used to encode the second word.

Although there are several theories available to account for the pupillary data, why the effect of spacing on retention was different in the two experiments must be explained. The pupillary data suggest that, when identical words are repeated, the results of earlier operations are easily retrieved. For spaced repetitions, the results of earlier operations cannot be retrieved easily and elaborations nust be performed again. Jacoby (1978) offered two possible interpretations of why retrieval of previous elaborations produces inferior retention compared with construction of elaborations. He suggests that the memorial traces of retrieved repetitions are less distinctive than the traces of constructed repetitions. Consequently, the traces of retrieved repetitions are more difficult to recognize (Jacoby \& Craik, 1978; Lockhart et al., 1976). Alternatively, he also suggested that constructed repetitions could be retained better because they are processed to a deeper level (Craik \& Lockhart, 1972) than are retrieved repetitions. Similar arguments have been offered by Rose (1980).

The frequency-judgment data of Experiment 2 produced the opposite pattern from that of Experiment 1: Massed presentations of related words produced better retention than did spaced presentations. According to the positions of Jacoby (1978) and Rose (1980; Rose \& Rowe, 1976), massed presentations should have traces that are less "rich" than the traces representing 
spaced presentations. To account for the frequencyjudgment data of Experiment 2, it must be assumed that those subjects used an organizational strategy that was not appropriate for the subjects in Experiment 1. Specifically, interitem associations were now easily formed for massed presentations, and such associations are an aid to retention (Glanzer, 1969), enough of an aide to offset the deleterious effects of massed presentations. The presence of pupillary constrictions and small dilations following massed related items in Experiment 2 suggests that these interitem associations can be formed without allocating effort. This is consistent with the positions of Ambler and Maples (1977) and Lucas and Bub (1981), who have argued that semantic organization can be performed by an automatic system that does not require mental capacity.

The formulation of the spacing effect supported here argues that less processing is allocated to massed repetitions than to spaced repetitions. Massed repetitions of identical words are, therefore, not as easily retrieved. This viewpoint is similar to that of Hyde and Jenkins (1969, 1973) and Craik and Tulving (1975), who argue it is the process engaged in, not the intention to remember, that is important. Similar mechanisms are at work when the spacing between pairs of related words is varied. The effects of spacing length are now offset by organizational strategies that are facilitated by massed presentation.

Although the theories of Jacoby (1978) and Rose (1980; Rose \& Rowe, 1976) may provide a satisfactory account of the spacing effect, there is other evidence suggesting they are limited in generality. Glenberg and Lehmann (1980) showed that increasing the length of spacing up to 1 week can increase free recall. Examination of Figure 2 shows that the magnitude of pupil dilation (and, presumably, mental effort) reached an asymptote at a spacing of four. This suggests that another mechanism, unrelated to mental effort, may produce the spacing effect over these longer intervals.

The account of the spacing effect presented here, then, may be limited to the increases in retention as the spacing length is increased from approximately 0 to $12 \mathrm{sec}$. Although multiple accounts of the spacing effect would not be a parsimonious explanation of the phenomenon, Hintzman (1974, pp. 78-79) also argued that the spacing effect produced by variations in long spacings (i.e., greater than $15 \mathrm{sec}$ ) is a different phenomenon from the spacing effect caused by variations in short spacings $(0-15 \mathrm{sec})$.

\section{REFERENCES}

Amblen, B., \& MAPLes, W. Role of rehearsal in encoding and organization for free recall. Journal of Experimental Psychology: Human Learning and Memory, 1977, 3, 295-304.

Battig, W. F., \& Montague, W. E. Category norms for verbal items in 56 categories: A replication and extension of the Connecticut category norms. Journal of Experimental Psychology Monograph, 1969, 80(3, Pt. 2).

Bertelson, P. S-R relationships and reaction times to new versus repeated signals in a serial task. Journal of Experimental Psychology, 1963, 65, 478-484.

Craik, F. I. M., \& Lockhart, R. S. Levels of processing: A framework for memory research. Journal of Verbal Learning and Verbal Behavior, 1972, 11, 671-684.

Craik, F. I. M., \& Tulving, E. Depth of processing and the retention of words in episodic memory. Journal of Experimental Psychology: General, 1975, 104, 268-294.

DAvis, M. Effects of interstimulus interval length and variability on startle response habituation in rats. Journal of Comparative and Physiological Psychology, 1970, 72, 177-192.

Fischler, I., \& Goodman, G. O. Latency of associative activation in memory. Journal of Experimental Psychology: Human Perception and Performance, 1978, 4, 455-470.

Gatchel, R. J., \& GAss, E. Effects of arousal level on shortand long-term habituation of the orienting response. Physiological Psychology, 1976, 4, 66-68.

Glanze R, M. Distance between related words in free recall: Trace of the STS. Journal of Verbal Learning and Verbal Behavior, $1969,8,105-111$.

Glenberg, A. M., \& Lehman, T. S. Spacing repetitions over 1 week. Memory \& Cognition, 1980, 8, 528-538.

Graham, F. K. Analyses of heart rate response curves: A comment on pooled interaction terms. Psychophysiology, 1970, 7, 485-489.

Graham, F. K. Habituation and dishabituation of responses enervated by the autonomic nervous system. In H. V. S. Peeke \& M. J. Herz (Eds.), Habituation(Vol. 1): Behavioral studies. New York: Academic Press, 1973.

Hintzman, D. L. Theoretical implications of the spacing effect. In R. L. Solso (Ed.), Theories in cognitive psychology: The Loyola symposium. Potomac, Md: Erlbaum, 1974.

Hintzman, D. L., \& Stern, L. D. Failure to confirm Elmes, Greener, and Wilkinson's finding on the spacing effect. American Journal of Psychology, 1977, 90, 489-497.

Hintzman, D. L., Summers, J. J., \& Block, R. A. Spacing judgments as an index of study-phase retrieval. Journal of Experimental Psychology: Human Learning and Memory, 1975, 1, 31-40. (a)

Hintzman, D. L., Summens, J. J., \& Block, R. A. What causes the spacing effect? Some effects of repetition, duration, and spacing on memory for pictures. Memory \& Cognition, 1975, 3, 287-294. (b)

Hintzman, D. L., Summers, J. J., Eki, N. T., \& Moore, M. D. Voluntary attention and the spacing effect. Memory \& Cognition, 1975, 3, 576-580.

Hyde, T. S., \& JEnkins, J. J. The differential effects of incidental tasks on the organization of recall of a list of highly associated words. Journal of Experimental Psychology, 1969, 82, $471-492$.

HyDE, T. S., \& JENKINS, J. J. Recall for words as a function of semantic, graphic, and syntactic orienting tasks. Journal of Verbal Learning and Verbal Behavior, 1973, 12, 471-480.

JACOBY, L. L. On interpreting the effects of repetition: Solving a problem versus remembering a solution. Journal of Verbal Learning and Verbal Behavior, 1978, 17, 649-667.

JACOBY, L. L., \& CRAIK, F. I. M. Effects of elaboration of processing at encoding and retrieval: Trace distinctiveness and recovery on initial context. In L. S. Cermak \& F. I. M. Craik (Eds.), Levels of processing and human memory. Hillsdale, N.J: Erlbaum, 1978.

Johnston, W. A., \& Uhь, C. N. The contributions of encoding effort and variability to the spacing effect on free recall. Journal of Experimental Psychology: Human Learning and Memory, $1976,2,153-160$.

Kahneman, D. Attention and effort. Englewood Cliffs, N.J: Prentice-Hall, 1973.

Kahneman, D., \& Beatty, J. Pupil diameter and load on memory. Science, 1966, 154, 1583-1585.

Kahneman, D., Beatty, J., \& Pollack, I. Perceptual deficit during a mental task. Science, 1967, 157, 218-219.

Kahneman, D., \& Peavler, W. S. Incentive effects and pupil- 
lary changes in association learning. Journal of Experimental Psychology, 1969, 79, 312-318.

KEELE, S. W. Repetition effect: A memory dependent process. Journal of Experimental Psychology, 1969, 80, 243-248.

Lockhart, R. S., Craik, F. I. M., \& Jacoby, L. L. Depth of processing, recognition, and recall: Some aspects of a general memory system. In J. Brown (Ed.), Recall and recognition. London: Wiley, 1976.

LuCAs, M., \& BuB, D. Can practice result in the ability to divide attention between two complex language tasks? Comment on Hirst et al. Journal of Experimental Psychology: General, 1981, 110, 495-498.

McFarland, C. E., Rhodes, D. D., \& Faey, T. J. Semantic feature variability and the spacing effect. Journal of Verbal Learning and Verbal Behavior, 1979, 18, 63-172.

NEELY, J. N. Semantic priming and retrieval from lexical memory: Roles of inhibitionless spreading activation and limited-capacity attention. Journal of Experimental Psychology: General, 1977, 106, 226-254.

Posner, M. I., \& Bores, S. J. Components of attention. Psychological Review, 1971, 78, 391-408.

Posner, M. I., \& SNyder, C. R. R. Facilitation and inhibition in the processing of signals. In P. M. A. Rabbitt (Ed.), Attention and performance $V$. New York: Academic Press, 1975.

Rose, R. J. Encoding variability, levels of processing, and the effects of spacing of repetitions upon judgments of frequency. Memory \& Cognition, 1980, 8, 84-93.

Rose, R. J., \& RowE, E. J. Effects of orienting task spacing of repetitions and list context on judgments of frequency. Journal of Experimental PSychology: Human Learning and Memory, $1976,2,142-152$

Shapiro, S. I., \& Palermo, D. S. Conceptual organization and class membership: Normative data for representatives of 100 categories. Psychonomic Monograph Supplements, 1970, 3(11, Whole No. 43).
Shaughnessy, J. J., Zimmerman, J,, \& Underwood, B. J. Further evidence on the MP-DP effect in free recall learning. Journal of Verbal Learning and Verbal Behavior, 1972, 11, 1-12. Silverste in, L. D. Repetition and distribution effects on memory: A psychophysiological analysis. Unpublished doctoral dissertation, University of Florida, 1977.

UNDERWOOD, B. J. Some correlates of item repetition in freerecall learning. Journal of Verbal Learning and Verbal Behavior, $1969,8,83-94$.

\section{NOTES}

1. Some additional points should be made about the construction of the lists. First, although the items were not counterbalanced against repetition conditions, an examination of the lists shows that no systematic bias was present. Second, no proper-name categories were used. Obviously, the 96 categories were not all distinct, but this should not influence the results.

2. Experiments 1 and 2 both had high attrition rates because of the difficulty in measuring pupil diameter. Frequency judgments were collected from all subjects to check for a possible attrition bias. The subjects eliminated from consideration because of poor video recordings exhibited the same frequencyjudgment results as those subjects whose data are reported here. Additionally, the subjects eliminated from consideration were divided equally among the three lists in both experiments.

3. The probability of a Type I error was set at .05 for all statistical tests.

4. Since the primary physiological variable was pupil dilation, a 6-sec ISI was used, despite the possible disruption of heart rate responses.

(Manuscript received September 28, 1982; revision accepted for publication June $29,1983$. ) 